\title{
The Crystal Structure of Potassium Hydrogen Oxalate, $\mathrm{KHC}_{2} \mathrm{O}_{4}$
}

\author{
BER I T F. PEDERSEN
}

Central Institute for Industrial Research, Oslo 3, Norway

\begin{abstract}
Potassium hydrogen oxalate, $\mathrm{KHC}_{2} \mathrm{O}_{4}$, crystallizes in the monoclinic system, space group $P 2_{1} / c$. The hydrogen oxalate ion is found to be non-planar. Each of the two $\mathrm{C}-\mathrm{C}-\mathrm{O}_{2}$-groups in the ion is planar, but the two planes are twisted $12.7^{\circ}(0.6)$. The $\mathrm{C}-\mathrm{O}$ distances are 1.297(9) $\AA, 1.267(9) \AA, 1.229(9) \AA$, and $1.218(9) \AA$, and the $\mathrm{C}-\mathrm{C}$ distance is $1.543(10) \AA$. Both $\mathrm{O}-\mathrm{C}-\mathrm{O}$ angles are greater than $120^{\circ}$ : 123.1(.6 $)^{\circ}$ and $127.7(.6)^{\circ}$, respectively. The crystal is built up of infinite chains of hydrogen oxalate ions held together by short hydrogen bonds of $2.534(8) \AA$ parallel to the $(10 \overline{2})$ planes. The hydrogen bonded oxygen atoms are situated cis to one another, thus leaving the other half of the oxalate ion free to coordinate to the potassium ions, which are situated between the oxalate chains. The potassium ion has seven nearest oxalate oxygens originating from five different hydrogen oxalate ions at distances from 2.704 to $2.964(7) \AA$. Infrared spectra of the compound and of its deuterated analog, $\mathrm{KDC}_{2} \mathrm{O}_{4}$, have been recorded and compared to spectra of alkalimetal oxalates obtained earlier.
\end{abstract}

\footnotetext{
The crystal structure of potassium hydrogen oxalate was studied by Hendricks in $1935 .^{1}$ His structure analysis was based on a planar and centrosymmetric hydrogen oxalate ion, but he was unable to find a unique solution. A structure investigation of $\mathrm{K}\left(\mathrm{HC}_{2} \mathrm{O}_{4}\right)\left(\mathrm{H}_{2} \mathrm{C}_{2} \mathrm{O}_{4}\right) \cdot 2 \mathrm{H}_{2} \mathrm{O}$ carried out by Haas, ${ }^{2}$ however, shows the $\mathrm{HC}_{2} \mathrm{O}_{4}^{-}$ion in this compound to be non-planar, the angle of twist between the two $\mathrm{C}-\mathrm{C}-\mathrm{O}_{2}$-planes being $6.1^{\circ}$, whereas a recent neutron diffraction analysis of $\left(\mathrm{NH}_{4}\right) \mathrm{HC}_{2} \mathrm{O}_{4} \cdot \mathrm{H}_{2} \mathrm{C}_{2} \mathrm{O}_{4} \cdot 2 \mathrm{H}_{2} \mathrm{O}$ shows the $\mathrm{HC}_{2} \mathrm{O}_{4}^{-}$ion in this compound to be planar. ${ }^{3}$ As the space group symmetry in $\mathrm{KHC}_{2} \mathrm{O}_{4}$ leaves no requirements neither on planarity nor on symmetry of the oxalate ion, it was found of interest to determine the crystal structure in detail, thereby establishing the conformation of the hydrogen oxalate ion and the hydrogen bonding scheme.
} 


\section{EXPERIMENTAL}

Well formed crystals of potassium hydrogen oxalate separated from a water solution of equivalent amounts of potassium oxalate and oxalic acid by slow evaporation of the solvent at room temperature. Potassium deuterium oxalate was made similarly by dissolving potassium hydrogen oxalate in $\mathrm{D}_{2} \mathrm{O}$, and recrystallizing the separated compound.

The unit cell dimensions of potassium hydrogen oxalate were determined from oscillation and Weissenberg diagrams and refined by Guinier powder patterns using $\mathrm{CuK} \alpha_{1}$ radiation and $\mathrm{KCl}$ as internal standard. Observed and calculated $\sin ^{2} \theta$ values are given in Table 1. The lattice constants determined are:

$$
a=4.319 \AA, b=12.890 \AA, c=7.660 \AA, \beta=101.96^{\circ}
$$

With four formula units in the cell a density of $2.06 \mathrm{~g} / \mathrm{cm}^{3}$ is derived which is the same as the density determined by the floatation method. Absent spectra are: $h 0 l, l=2 n+1$, and $0 k 0, k=2 n+1$, which unambiguously determine the space group to be No. $14 P 2_{1} / c .^{4}$

A small diamond shaped crystal was mounted to oscillate about the $a$-axis. Using $\mathrm{Ni}$-filtered $\mathrm{Cu}$-radiation multiple film integrated Weissenberg diagrams were taken of zero-, first-, and second-layers along this axis and of zero-, first-, second-, and thirdlayers with the crystal oscillating about the $b$-axis.

The integrated reflections were measured photometrically, except the very weakest ones which were estimated visually by comparison with a calibrated scale. The number of recorded reflections were about 450 , and about 100 of these had unobservable intensities. The intensities for the unobserved reflections were set equal to half the minimum observable value. All intensities were corrected in the usual way for Lorentz-and polarization effects, and the structure amplitudes derived. The unobserved reflections were included in the structure factor calculations, but omitted from the least squares refinement.

The linear absorption coefficient for $\mathrm{CuK} \alpha$ radiation is $103 \mathrm{~cm}^{-1}$, but because of the irregular shape of the crystals no absorption correction has been applied. Six of the strongest reflections seem to suffer from extinction. No correction has been applied, but these six reflections were omitted from the least squares calculation in the last cycles of refinement. The scattering factors used in the calculations were taken from International Tables (1962). ${ }^{\circ}$

The infrared spectrum and the X-ray powder diffractogram of the deuterated compound were run immediately after preparation to minimize deuterium-hydrogen exchange. The infrared spectra of potassium hydrogen oxalate and potassium deuterium oxalate were recorded on a Perkin-Elmer Model 21 infrared spectrophotometer equipped with $\mathrm{NaCl}$ optics. Experimental details are described elsewhere. ${ }^{6}$

The X-ray diffractograms of $\mathrm{KDC}_{2} \mathrm{O}_{4}$ and $\mathrm{KHC}_{2} \mathrm{O}_{4}$ were recorded on a $\mathrm{GE}$ spectrogoniometer using slow scan and a silicon standard as reference.

\section{STRUCTURE DETERMINATION}

The $y$ and $z$ parameters of the potassium atom were determined from the Patterson projection along the $a$-axis. The corresponding projection of the crystal structure was solved by the heavy atom method and by the use of the Patterson map in interpreting the first Fourier map. The (0kl) data were then subject to least squares refinement using isotropic thermal parameters, giving $R=0.09$. The $x$-parameters were estimated from projections of calculated interatomic distances and packing considerations. Two sets of possible $x$ parameters were derived in this way, and with those as input variables threedimensional least squares refinement was performed ${ }^{7}$ allowing only the $x$ parameters and the isotropic thermal parameters to vary. Only one of these sets refined satisfactorily, to an $R$-value of 0.11 . Further refinement of all parameters introducing anisotropic thermal parameters for the potassium 
Table 1. Guinier powder pattern of $\mathrm{KHC}_{2} \mathrm{O}_{4} \cdot \mathrm{CuK \alpha _{1 }}$ radiation.

\begin{tabular}{|c|c|c|c|}
\hline Intensity & $h k l$ & $\sin ^{2} \theta_{\text {obs }}$ & $\sin ^{2} \theta_{\text {calc }}$ \\
\hline $\mathrm{w}$ & 110 & 0.03673 & 0.03681 \\
\hline $\mathbf{w}$ & $11 \overline{1}$ & 0.03951 & 0.03960 \\
\hline $\mathbf{m}$ & 002 & 0.04221 & 0.04225 \\
\hline s & $12 \bar{I}$ & 0.05035 & 0.05032 \\
\hline $\mathrm{m}$ & 111 & 0.05507 & 0.05514 \\
\hline $\mathrm{m}$ & 022 & 0.05648 & 0.05654 \\
\hline $\mathrm{w}$ & $10 \overline{2}$ & 0.06000 & 0.05996 \\
\hline $\mathbf{s}$ & $11 \overline{2}$ & 0.06346 & 0.06353 \\
\hline $\mathrm{s}$ & 130 & 0.06533 & 0.06538 \\
\hline $\mathrm{s}$ & 041 & 0.06773 & 0.06770 \\
\hline$s-m$ & 032 & 0.07440 & 0.07439 \\
\hline $\mathrm{m}$ & 102 & 0.09101 & 0.09102 \\
\hline $\mathrm{m}$ & $14 \overline{1}$ & 0.09313 & 0.09304 \\
\hline $\mathrm{m}$ & 112 & 0.09483 & 0.09459 \\
\hline $\mathrm{m}$ & 013 & 0.09864 & 0.09864 \\
\hline $\mathrm{m}$ & 122 & 0.10535 & 0.10531 \\
\hline$s-m$ & 023 & 0.10951 & 0.10935 \\
\hline $\mathrm{s}$ & 132 & 0.12326 & 0.12316 \\
\hline$w$ & $15 \overline{\mathrm{l}}$ & 0.12509 & 0.12531 \\
\hline $\mathrm{m}$ & 060 & 0.12856 & 0.12856 \\
\hline $\mathrm{m}$ & 052 & 0.13162 & 0.13153 \\
\hline$m-s$ & 200 & 0.13295 & 0.13295 \\
\hline & 210 & & 0.13652 \\
\hline $\mathbf{m}$ & $13 \overline{\mathbf{3}}$ & 0.13659 & 0.13668 \\
\hline $\mathrm{w}$ & 151 & 0.14097 & 0.14084 \\
\hline $\mathrm{w}$ & 220 & 0.14717 & 0.14723 \\
\hline $\mathrm{w}$ & $15 \overline{2}$ & 0.14936 & 0.14923 \\
\hline $\mathrm{m}$ & 043 & 0.15238 & 0.15220 \\
\hline & 113 & 0.15510 & 0.15518 \\
\hline $\mathrm{m}$ & $10 \overline{4}$ & 0.16237 & 0.16262 \\
\hline $\mathrm{m}$ & 014 & 0.17256 & 0.17258 \\
\hline
\end{tabular}

atom and omitting structure factors calculated less than the minimum observable value gave the reliability index $R=0.076$.

By omitting 6 reflections, obviously suffering from extinction, the value reached 0.072. Anisotropic thermal parameters were then introduced for

Table 2. Atomic coordinates with standard deviations $\left(\times 10^{4}\right)$.

\begin{tabular}{|c|c|c|c|}
\hline & $x$ & $y$ & $z$ \\
\hline $\begin{array}{l}\mathrm{K}^{+} \\
\mathrm{O}_{1} \\
\mathrm{O}_{2} \\
\mathrm{O}_{3} \\
\mathrm{O}_{4} \\
\mathrm{C}_{1} \\
\mathrm{C}_{2} \\
\mathrm{H}^{-}\end{array}$ & $\begin{array}{l}8133(6) \\
3378(16) \\
8559(17) \\
2507(18) \\
7060(17) \\
4016(24) \\
6793(28) \\
1400\end{array}$ & $\begin{array}{r}692(1) \\
2306(5) \\
2697(5) \\
3990(5) \\
4353(5) \\
3271(7) \\
3475(7) \\
2700\end{array}$ & $\begin{array}{c}2271(3) \\
864(9) \\
3334(10) \\
481(10) \\
3495(9) \\
1268(12) \\
2854(13) \\
4800\end{array}$ \\
\hline
\end{tabular}

Acta Chem. Scand. 22 (1968) No. 9 
Table 3. Anisotropic thermal parameters with standard deviation $\left(\times 10^{4}\right)$. The form of the temperature factor is: $\exp -\left(\beta_{31} h^{2}+\beta_{22} k^{2}+\beta_{33} l^{2}+\beta_{18} h k+\beta_{13} h l+\beta_{23} k l\right)$.

\begin{tabular}{|c|c|c|c|c|c|c|}
\hline & $\beta_{11}$ & $\beta_{22}$ & $\beta_{33}$ & $\beta_{12}$ & $\beta_{13}$ & $\beta_{23}$ \\
\hline $\mathbf{k}+$ & $311(18)$ & $24(1)$ & $100(3)$ & $-19(10)$ & $-133(12)$ & $-8(4)$ \\
\hline $\mathrm{O}_{1}$ & $279(57)$ & $24(3)$ & $101(13)$ & $6(26)$ & $-21(44)$ & $-19(11)$ \\
\hline $\mathrm{O}_{2}$ & $442(70)$ & $29(4)$ & $136(14)$ & $64(29)$ & $-203(51)$ & $-3(12)$ \\
\hline $\mathrm{O}_{3}$ & $598(15)$ & $30(4)$ & $162(5)$ & $10(33)$ & $-319(58)$ & $10(13)$ \\
\hline $\mathrm{O}_{4}$ & $445(68)$ & $33(4)$ & $124(13)$ & $12(33)$ & $-79(51)$ & $-9(13)$ \\
\hline $\mathrm{C}_{1}$ & $267(94)$ & $25(5)$ & $81(16)$ & $106(40)$ & $-65(66)$ & $4(16)$ \\
\hline $\mathrm{C}_{2}$ & $375(91)$ & $27(5)$ & $105(17)$ & $-57(44)$ & $-51(68)$ & $2(17)$ \\
\hline
\end{tabular}

the oxygen and carbon atoms, resulting in a very slight change in positional parameter values, giving $R=0.058$. A total difference map was calculated based on the parameters from the last refinement, using only reflections where $\sin \theta \mid \lambda<0.4$. However, no unambiguous position for the hydrogen atom could be found. A tentative position was chosen, and the hydrogen atom with an isotropic thermal parameter was included in the last cycles of least squares

Table 4. Root mean square vibrational displacement ( $\AA$ ) along the principal axes of the thermal ellipsoids, and components of the displacement along the direct cell edges.

\begin{tabular}{cccccr}
\hline Atom & $\begin{array}{c}\text { Principal } \\
\text { axes }\end{array}$ & $\sqrt{\overline{\bar{u}}^{2}}$ & $u_{x}$ & \multicolumn{1}{c}{$u_{y}$} & \multicolumn{1}{c}{$u_{z}$} \\
\hline & 1 & & & & \\
$\mathrm{~K}^{+}$ & 2 & 0.22 & 0.14 & 0 & -0.14 \\
& 3 & 0.15 & 0.04 & -0.14 & 0.05 \\
& 1 & 0.19 & 0.09 & 0.04 & 0.08 \\
$\mathrm{O}_{1}$ & 2 & 0.15 & 0.10 & 0.05 & -0.14 \\
& 3 & 0.13 & 0.12 & -0.08 & 0.07 \\
& 1 & 0.27 & -0.18 & -0.04 & 0.07 \\
$\mathrm{O}_{2}$ & 2 & 0.16 & -0.06 & -0.14 & -0.09 \\
& 3 & 0.13 & -0.09 & 0.07 & -0.08 \\
& 1 & 0.30 & -0.21 & 0 & 0.19 \\
$\mathrm{O}_{3}$ & 2 & 0.16 & -0.05 & -0.15 & -0.05 \\
& 3 & 0.14 & -0.10 & 0.05 & -0.11 \\
& 1 & 0.24 & 0.17 & 0.03 & -0.14 \\
$\mathrm{O}_{4}$ & 2 & 0.17 & 0.05 & -0.16 & 0.04 \\
& 3 & 0.16 & 0.11 & 0.06 & 0.13 \\
& & & & & \\
$\mathrm{C}_{1}$ & 1 & 0.21 & -0.15 & -0.10 & 0.08 \\
& 2 & 0.15 & -0.03 & -0.09 & -0.13 \\
& 3 & 0.08 & -0.06 & 0.05 & -0.03 \\
$\mathrm{C}_{2}$ & 1 & 0.22 & 0.16 & -0.06 & -0.11 \\
& 2 & 0.16 & 0.07 & -0.09 & 0.13 \\
& 3 & 0.13 & 0.08 & 0.10 & 0.05
\end{tabular}




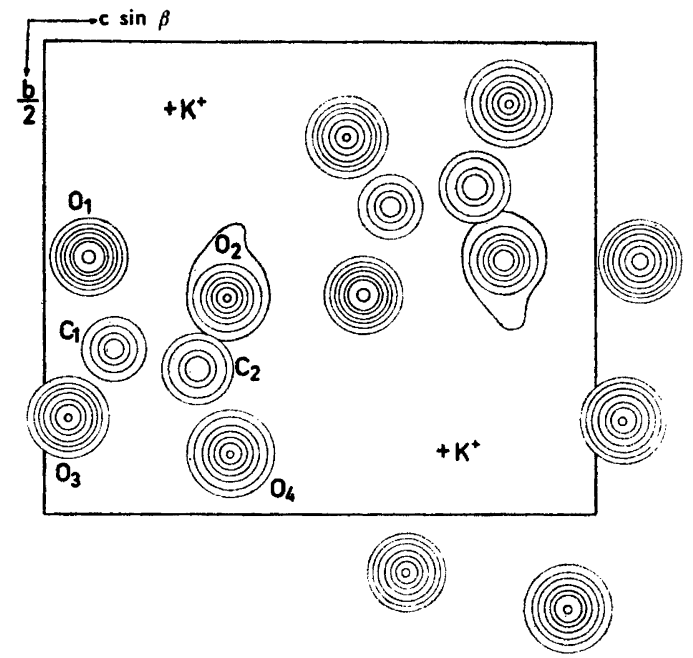

Fig. 1. Composite Fourier map of $\mathrm{KHC}_{2} \mathrm{O}_{4}$. The $\mathrm{K}^{+}$ions are subtracted and their positions marked by crosses in the map.

refinement, whereby the $R$-index dropped to 0.056 . The results of these calculations are given in Tables 2 and 3.

From the anisotropic thermal parameters given in Table 3 the root mean square atomic displacements along the principal axes of the thermal ellipsoides were calculated. The result of this analysis is given in Table 4. Table 5 gives the observed and calculated structure factors, and Table 6 gives calculated interatomic distances and angles. The final composite Fourier map with the potassium atoms subtracted for clarity is shown in Fig. 1.

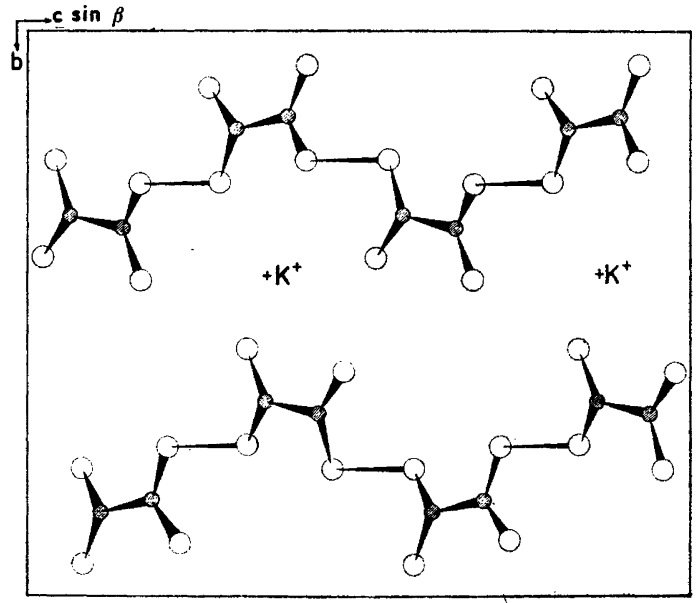

Fig. 2. Packing relations in $\mathrm{KHC}_{2} \mathrm{O}_{4}$ viewed along the $a$-axis. $\mathrm{K}^{+}$ions marked by crosses. Acta Chem. Scand. 22 (1968) No. 9 
Table 5. Observed and calculated structure factors.

\begin{tabular}{|c|c|c|c|c|c|c|c|c|}
\hline $\mathbf{h}$ & k & 1 & $F_{\text {obs }}$ & $F_{\text {cale }}$ & $\mathrm{h}$ & k & 1 & $F_{\text {obs }}$ \\
\hline $\begin{array}{l}0 \\
0\end{array}$ & $\begin{array}{r}t \\
10\end{array}$ & u & $\begin{array}{l}32.144 \\
19.57\end{array}$ & $\begin{array}{r}-32.53 \\
-19.69\end{array}$ & 1 & $t$ & 4 & 14.30 \\
\hline$v$ & 1 & 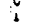 & 5.16 & $\begin{array}{r}-19.69 \\
3 .>8\end{array}$ & $\begin{array}{l}1 \\
1\end{array}$ & $\begin{array}{l}5 \\
4\end{array}$ & $\begin{array}{l}4 \\
4\end{array}$ & $\begin{array}{r}11.84 \\
5.15\end{array}$ \\
\hline 6 & 2 & $i$ & 7.00 & 7.82 & $i$ & 3 & 4 & 24.07 \\
\hline i & 3 & $i$ & 0.94 & 4.09 & 1 & 2 & 4 & 0.10 \\
\hline$u$ & 5 & 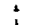 & 20.73 & $20 . A 6$ & 1 & 3 & 5 & 14.37 \\
\hline$u$ & 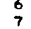 & 1 & 15.44 & $=16.13$ & 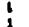 & 2 & 3 & 16.47 \\
\hline$u$ & 6 & 1 & $\begin{array}{l}26.46 \\
15.86\end{array}$ & $\begin{array}{r}-26.06 \\
15.04\end{array}$ & 1 & $\begin{array}{l}1 \\
0\end{array}$ & $\begin{array}{l}5 \\
2\end{array}$ & $\begin{array}{l}35.74 \\
36.90\end{array}$ \\
\hline$u$ & 10 & $i$ & $|A \cdot 3|$ & 18.15 & 0 & 0. & 4 & $7: 10$ \\
\hline u & $i$ & 2 & $15.7 \mathrm{~B}$ & -14.46 & 1 & & 2 & 01.77 \\
\hline 0 & 5 & 2 & 0.27 & ${ }^{H} .13$ & 2 & 0 & -4 & 11.91 \\
\hline$u$ & $t$ & 2 & 14.45 & 19.94 & 2 & 0 & 0 & 73.05 \\
\hline u & 7 & 2 & 3.35 & $3 .+3$ & 2 & 0 & 2 & 48.74 \\
\hline$u$ & B & c & 35.23 & 36.20 & 2 & 0 & 4 & 19.76 \\
\hline$u$ & 9 & 2 & 0.71 & $\mu .76$ & 3 & 0 & -4 & $27.6 z$ \\
\hline$\iota$ & 1 & 2 & 4.3 .77 & -44.18 & 3 & 0 & -2 & 25.91 \\
\hline$u$ & 2 & 2 & 41.94 & 44.05 & 3 & 9 & 0 & 12.06 \\
\hline & 4 & 3 & 21.74 & 55.03 & i & 2 & 2 & 30.76 \\
\hline 0 & b & 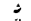 & 10.07 & 19.52 & 1 & 2 & -4 & 17.74 \\
\hline$i$ & 6 & 3 & 0.27 & 9.24 & 2 & 2 & -2 & 28.94 \\
\hline$u$ & 7 & 3 & 30.53 & 31.77 & 1 & 2 & 0 & $2 H_{0} 11$ \\
\hline 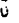 & b) & 3 & $111 . \mathrm{HC}$ & -0.04 & 2 & 2 & -4 & 14.45 \\
\hline u & 1 & 4 & $311.4 \mathrm{c}$ & -31.58 & 2 & 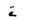 & -3 & 21.14 \\
\hline 0 & 2 & 4 & 39.112 & 32.06 & 2 & 2 & $-i$ & 13. 177 \\
\hline 0 & 3 & 4 & $10 . \mathrm{Rl}$ & 20.19 & 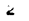 & 2 & $-i$ & $10 . n z$ \\
\hline$v$ & 4 & 4 & 10.70 & $-20 \cdot 11$ & 2 & $z$ & 2 & $<3.42$ \\
\hline v & $s$ & 4 & X.sc & -1.70 & $<$ & $\bar{c}$ & 3 & $24.10 i$ \\
\hline 4 & $\epsilon$ & 4 & 1.0 .01 & -13.50 & 3 & 2 & -3 & 18.74 \\
\hline i & 7 & 4 & 14.44 & 15.52 & 3 & $\dot{z}$ & $-i$ & b.25 \\
\hline u & $:$ & ? & 2110.14 & 23.40 & 3 & 2 & " & 10.24 \\
\hline$\checkmark$ & 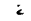 & 2 & $4.3^{34}$ & $-<0.70$ & 3 & . & $i$ & (1.) \\
\hline$u$ & 4 & 2 & ds.h $^{\circ}$ & -17.70 & 2 & 3 & $-c$ & 17.70 \\
\hline$u$ & y & $=$ & (.5) & -0.19 & $c$ & 3 & -1 & 11.02 \\
\hline 1 & 1 & c & $10 . \mathrm{HE}$ & $2^{\mu} \cdot ? 5$ & 2 & 3 & $i$ & 111.35 \\
\hline 1 & 4 & u & 7.49 & 7.11 & 2 & 3 & 1 & 11.37 \\
\hline 1 & $s$ & t & 30.91 & 44.51 & 2 & 3 & $<$ & $<1.2<$ \\
\hline 1 & 6 & $i$ & 22.20 & -22.46 & 4 & 1 & -4 & 10.34 \\
\hline 1 & 7 & $\dot{0}$ & $10.11=$ & 14.96 & 1 & 1 & -3 & 10.72 \\
\hline 4 & 5 & 0 & 14.72 & -1.3 .30 & 1 & 1 & -1 & 211.29 \\
\hline 1 & 3 & -1 & -3.57 & $-2 \AA .06$ & 1 & 1 & 4 & 20.04 \\
\hline 1 & 4 & $-i$ & 41.40 & $47 \cdot+36$ & 2 & 1 & -5 & 45.05 \\
\hline 1 & 5 & $-i$ & 32.24 & 33.75 & 2 & 1 & -1 & 40.06 \\
\hline 1 & 0 & $-i$ & 5.51 & -4.29 & 2 & 1 & i & $4 \pi .40$ \\
\hline$i$ & 7 & $-i$ & $23.7 i$ & 22.01 & $<$ & 1 & 1 & 35.64 \\
\hline$i$ & 15 & $-i$ & 10.25 & $-14,83$ & 3 & 1 & $-a$ & 17.47 \\
\hline i & 0 & -2 & 38.76 & 39.24 & 2 & 4 & -1 & 12.94 \\
\hline 1 & 3 & -2 & 14.70 & -18.84 & $\overline{2}$ & 5 & $-i$ & 11.70 \\
\hline 1 & 5 & -2 & 55.64 & -37.92 & 2 & 7 & -1 & 27.90 \\
\hline 1 & c. & $-i$ & 7.26 & 6.05 & 2 & $b$ & -2 & 7.63 \\
\hline & 7 & $-c$ & $11 . n d$ & 12.044 & 2 & 7 & -6 & 7.11 \\
\hline$i$ & th & $-i$ & 13.70 & 13.36 & 2 & 6 & -2 & 0.54 \\
\hline 1 & 9 & -2 & 12.53 & 10.18 & 2 & 5 & -2 & 23.25 \\
\hline 1 & $<$ & ذ- & $2 \pi .43$ & $-S H_{0} 90$ & 2 & 1 & -2 & 7.41 \\
\hline$\frac{1}{1}$ & 3 & $\Rightarrow$ & 27.33 & $27: 44$ & 2 & 3 & -3 & 3.04 \\
\hline 1 & 4 & -3 & 2.53 & -23.59 & ¿ & 4 & -3 & 24.02 \\
\hline 1 & $b$ & - & 12.46 & -12.28 & 2 & 5 & -3 & 20.52 \\
\hline & : & -2 & $\alpha P .06$ & $-2 H .47$ & 2 & 7 & $-j$ & $1 H . A C$ \\
\hline 1 & 7 & -3 & 21.31 & $-31,040$ & 2 & 3 & -4 & $1 A_{0} H_{2}$ \\
\hline 1 & $e$ & -3 & 7.00 & 7,05 & $\bar{z}$ & 4 & -4 & $3 . \mathrm{HO}$ \\
\hline 1 & $u$ & -4 & Sh.21 & $30 .>9$ & a & 3 & -4 & 20.07 \\
\hline 1 & 4 & -4 & $n_{0} 2_{k}$ & -7.33 & 2 & $i$ & -4 & 10.52 \\
\hline 1 & 6 & -4 & 25.12 & $-24 . t 9$ & 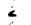 & $i$ & $\Rightarrow$ & 10.31 \\
\hline 1 & 7 & -4 & 7.21 & 0.07 & $<$ & $z$ & $j$ & 20.14 \\
\hline$i$ & 1 & - & 27.65 & -26.25 & 2 & 4 & $\mathrm{c}$ & T.tá \\
\hline 1 & $\ddot{z}$ & 2 & 23.00 & 22.10 & 2 & 6 & $u$ & 43.06 \\
\hline 2 & 3 & -5 & 7.30 & -5.16 & 2 & 8 & $i$ & $10.8 \bar{c}$ \\
\hline$i$ & 4 & $=$ & 2A. UO & 12.78 & 2 & 4 & i & 15.72 \\
\hline$i$ & 5 & - & 19.54 & $1+, 02$ & 2 & 5 & 1 & 36.60 \\
\hline$i$ & 0 & $=0$ & 14.78 & -13.28 & 2 & 6 & 1 & 22.92 \\
\hline i & 1 & $-c$ & 17.02 & $1 n .37$ & 2 & 7 & 1 & 12.70 \\
\hline 1 & q & 1 & 22.72 & -29.48 & 2 & 1 & $c$ & 3.115 \\
\hline 1 & 6 & 1 & 15.54 & -15.23 & 2 & 4 & $c$ & 3.55 \\
\hline 1 & 7 & 1 & 19.37 & $-1 \mathrm{H}$. & 2 & 5 & $\ddot{z}$ & 23.47 \\
\hline 1 & $b$ & 1 & $\mathrm{~A}_{\mathrm{B}} \mathrm{B}_{4}$ & $=-5.52$ & 2 & 4 & 3 & 41.90 \\
\hline I & b & 1 & 28,37 & -29.3 & 2 & $\epsilon$ & c & 13.03 \\
\hline 1 & 4 & 1 & 5.54 & 4.40 & 2 & 5 & us & $3 \alpha .16$ \\
\hline 1 & 3 & 2 & 14.17 & 23.5 & $z$ & 3 & -2 & 11.33 \\
\hline 1 & 2 & 1 & 15.21 & 12.73 & 2 & 2 & 1 & $7.7 ?$ \\
\hline 1 & 1 & $i$ & $\angle M_{0} B_{0}$ & 31.42 & $u$ & 12 & $u$ & $22.0<$ \\
\hline 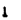 & 7 & $<$ & 5.70 & B. & 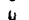 & is & 4 & 20.15 \\
\hline$i$ & 6 & 2 & 33.10 & 33. & 0 & 16 & 0 & $\begin{array}{r}0.15 \\
5,94\end{array}$ \\
\hline & 5 & 2 & 34.75 & 5. & 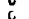 & 10 & 1 & $\begin{array}{rl}30.94 & 30.35\end{array}$ \\
\hline & 4 & 2 & 20.54 & -19.4 & 0 & 12 & 1 & 13.35 \\
\hline & 2 & $\ddot{z}$ & 20.07 & 24.3 & $u$ & 13 & 1 & 15.16 \\
\hline & $b$ & 2 & 33.28 & -34. & 0 & 14 & 1 & P.SC \\
\hline & 7 & 3 & 43.40 & 45.06 & 0 & 16 & l & 9.87 \\
\hline & 6 & 2 & 14.69 & $-14 \cdot 14$ & 6 & 10 & 2 & 22.41 \\
\hline & 3 & 2 & 14.19 & -13.82 & 0 & 12 & 2 & 11.79 \\
\hline & 2 & 3 & 15.49 & -14.41 & 0 & 13 & 2 & $R .54$ \\
\hline 1 & 1 & 3 & & $-28,20$ & 0 & 14 & 2 & 2.83 \\
\hline
\end{tabular}


Table 5. Continued.
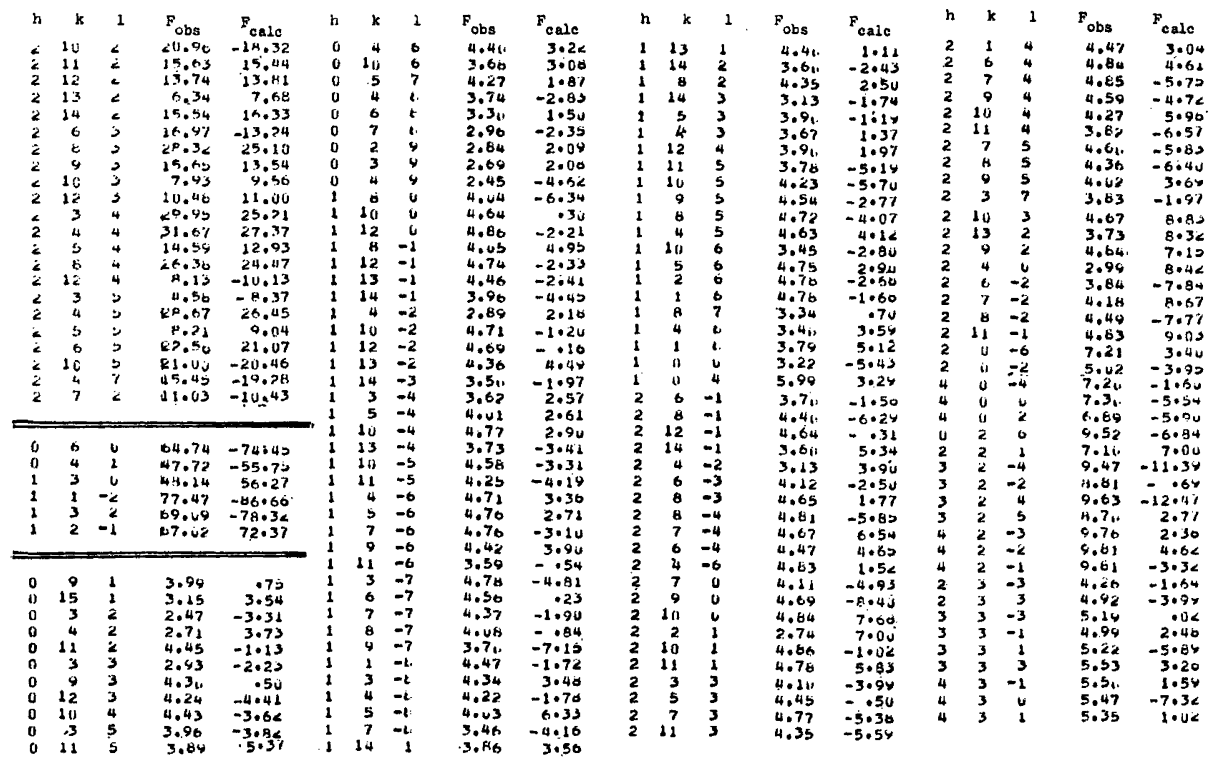

\section{DISCUSSION}

We will in this discussion first describe the packing of anions and cations, then the shape of the hydrogen oxalate ion and finally the hydrogen bonding scheme.

1. The packing and the shape of the hydrogen oxalate ion. Fig. 2 displays the packing relations in potassium hydrogen oxalate viewed along the $a$-axis.

Table 6. Interatomic distances and angles in the $\mathrm{HC}_{2} \mathrm{O}_{4}^{-}$ion.

$$
\begin{aligned}
& \mathrm{C}_{1}-\mathrm{O}_{1}=1.297 \pm(9) \AA \\
& \mathrm{C}_{2}-\mathrm{O}_{2}=1.267 \pm(9) \AA \\
& \mathrm{C}_{1}-\mathrm{O}_{3}=1.218 \pm(9) \AA \\
& \mathrm{C}_{2}-\mathrm{O}_{4}=1.229 \pm(9) \AA \\
& \mathrm{C}_{1}-\mathrm{C}_{2}=1.543 \pm(10) \AA \\
& \mathrm{O}_{1}-\mathrm{O}_{3}=2.212 \pm(8) \AA \\
& \mathrm{O}_{2}-\mathrm{O}_{4}=2.241 \pm(8) \AA
\end{aligned}
$$

Hydrogen bond distance:

$$
\begin{aligned}
& \text { Interionic distances: } \\
& \mathrm{K}-\mathrm{O}_{4^{\prime}=2.794 \pm(7)} \AA \\
& \mathrm{K}-\mathrm{O}_{4}^{\prime}=\mathbf{2 . 8 5 3} \pm(7) \AA \\
& \mathrm{K}-\mathrm{O}_{4}^{\prime}=\mathbf{2 . 8 3 4} \pm(7) \AA \\
& \mathrm{K}-\mathrm{O}_{1}^{\prime}=\mathbf{2 . 9 6 4} \pm(7) \AA
\end{aligned}
$$

$$
\begin{aligned}
& \angle \mathrm{O}_{1}-\mathrm{C}_{1}-\mathrm{O}_{3}=123.1^{\circ} \pm(0.6) \\
& \angle \mathrm{O}_{1}-\mathrm{C}_{1}-\mathrm{C}_{2}=116.4^{\circ} \pm(0.6) \\
& \angle \mathrm{O}_{3}-\mathrm{C}_{1}-\mathrm{C}_{2}=120.6^{\circ} \pm(0.6) \\
& \angle \mathrm{O}_{2}-\mathrm{C}_{2}-\mathrm{O}_{4}=127.7^{\circ} \pm(0.6) \\
& \angle \mathrm{O}_{2}-\mathrm{C}_{2}-\mathrm{C}_{1}=114.6^{\circ} \pm(0.6) \\
& \angle \mathrm{O}_{4}-\mathrm{C}_{2}-\mathrm{C}_{1}=117.7^{\circ} \pm(0.6)
\end{aligned}
$$

$$
\begin{aligned}
\mathrm{O}_{1}---\mathrm{O}_{2} & =2.534 \pm(8) \AA \\
\angle \mathrm{C}_{1}-\mathrm{O}_{1}-\mathrm{O}_{2} & =106.4 \pm(0.6)^{\circ}
\end{aligned}
$$

$$
\begin{aligned}
& \mathrm{K}-\mathrm{O}_{2^{\prime}}=2.704 \pm(7) \AA \\
& \mathrm{K}-\mathrm{O}_{3}{ }^{\prime}=2.799 \pm(7) \AA \\
& \mathrm{K}-\mathrm{O}_{3}=2.838 \pm(7) \AA \\
& \overline{\mathrm{KO}}=2.827 \AA
\end{aligned}
$$

Acta Chem. Scand. 22 (1968) No. 9 
The crystal is seen to consist of layers of anions alternating with cationic layers approximately parallel to the $(10 \overline{2})$ planes. The crystal shows a perfect cleavage along these planes, which is well understood on the basis of this packing mode. Each potassium ion is coordinated to seven oxalate oxygens originating from five different hydrogen oxalate ions, at distances from $2.704 \AA$ to $2.964( \pm 7) \AA$, with a mean $\mathrm{K}-\mathrm{O}$ distance of $2.827 \AA$, a value in good agreement with earlier observations. ${ }^{5}$

The anionic layers consist of infinite chains of hydrogen bonded hydrogen oxalate ions. The found atomic positions clearly show that the $\mathrm{HC}_{2} \mathrm{O}_{4}{ }^{-}$ion in $\mathrm{KHC}_{2} \mathrm{O}_{4}$ is non-planar. However, each of the two $\mathrm{C}-\mathrm{C}-\mathrm{O}_{2}$-groups in the ion is planar, but these two planes are twisted relative to each other about the $\mathrm{C}-\mathrm{C}$ bond. The equation to the plane through $\mathrm{O}(1) \mathrm{O}(3) \mathrm{C}(2)$ is:

$$
\text { I } \quad 0.70522 a x+0.02628 b y-0.70853 a z-0.63776=0
$$

and the equation to the plane through $\mathrm{O}(2) \mathrm{O}(4) \mathrm{C}(1)$ is:

$$
\text { II } \quad 0.66281 a x+0.24229 b y-0.70836 c z-1.48280=0
$$

The distance from $\mathrm{C}(2)$ to plane II is $0.001 \AA$ and the distance from $\mathrm{C}(1)$ to plane $I$ is $0.007 \AA$, and as the standard deviation for the carbon atoms is $0.007 \AA$ the two $\mathrm{C}-\mathrm{C}-\mathrm{O}_{2}$-groups are considered planar. The angle between the two planes is found to be $12.7^{\circ}(0.6)$. In $\mathrm{KHC}_{2} \mathrm{O}_{4} \cdot \mathrm{H}_{2} \mathrm{C}_{2} \mathrm{O}_{4} \cdot 2 \mathrm{H}_{2} \mathrm{O}$ the hydrogen oxalate ion has the same shape, but here the dihedral angle is $6.1^{\circ}$. A similarly twisted oxalate ion has also been found in $\left(\mathrm{NH}_{4}\right)_{2} \mathrm{C}_{2} \mathrm{O}_{4} \cdot \mathrm{H}_{2} \mathrm{O},{ }^{8}$ and in this case the angle of twist is $26.6^{\circ}$.

In all these structures the hydrogen bonds to the anions are probably responsible for the deviation from planarity. The hydrogen bonding scheme in $\mathrm{KHC}_{2} \mathrm{O}_{4}$ is also responsible for the lack of a centre of symmetry in the hydrogen oxalate ion, as the two oxygens engaged in hydrogen bonding are situated cis relative to one another in contrast to the ion in $\mathrm{KHC}_{2} \mathrm{O}_{4} \cdot \mathrm{H}_{2} \mathrm{C}_{2} \mathrm{O}_{4} \cdot 2 \mathrm{H}_{2} \mathrm{O}$ where these two oxygens are trans.

Comparison of the infrared spectra of $\mathrm{KHC}_{2} \mathrm{O}_{4}$ and $\mathrm{KDC}_{2} \mathrm{O}_{4}$ with infrared spectra recorded for similar compounds ${ }^{6}$ in which the oxalate ion is known to be centro-symmetric and planar reveals a striking difference. The number of absorption lines between 1800 and $1000 \mathrm{~cm}^{-1}$ in the spectra of $\mathrm{KHC}_{2} \mathrm{O}_{4}$ and $\mathrm{KDC}_{2} \mathrm{O}_{4}$ is far higher than for compounds containing a symmetric oxalate ion, indicating the presence of a lower symmetric ion. The frequencies observed for $\mathrm{KHC}_{2} \mathrm{O}_{4}$ and $\mathrm{KDC}_{2} \mathrm{O}_{4}$ are listed in Table 7 , and the spectra are reproduced in Fig. 3.

A detailed band assignment seems to be rather difficult. Frequencies common to both compounds should be attributable to the oxalate ion. Similar bands have been observed earlier in bidentate oxalate complexes ${ }^{9}$ and in oxalic acid. ${ }^{10}$

2. The dimensions of the hydrogen oxalate ion. Fig. 4 shows the $\mathrm{HC}_{2} \mathrm{O}_{4}^{-}$ ion with the bond lengths and angles determined from this investigation, and the same ion with the dimensions determined by Haas. ${ }^{2}$ The ion seems to possess the characteristics of both the oxalate ion and the oxalic acid molecule as most clearly shown in the length of the $\mathrm{C}-\mathrm{O}$ distances. The two $\mathrm{C}-\mathrm{O}$ bonds not engaged in hydrogen bonding are short, about $1.22 \AA$, whereas 
Table \%. Observed infrared frequencies for $\mathrm{KHC}_{2} \mathrm{O}_{4}$ and $\mathrm{KDC}_{2} \mathrm{O}_{4}$ in $\mathrm{cm}^{-1} \cdot{ }^{a}$

\begin{tabular}{cc}
\hline $\mathrm{KHC}_{2} \mathrm{O}_{4}$ & $\mathrm{KDC}_{2} \mathrm{O}_{4}$ \\
\hline $708 \mathrm{~s}$ & $675 \mathrm{~s}$ \\
& $712 \mathrm{vw}$ \\
$846 \mathrm{w}$ & $735 \mathrm{w}$ \\
$868 \mathrm{w}$ & $849 \mathrm{w}$ \\
$1101 \mathrm{~m}$ & $864 \mathrm{w}$ \\
$1204 \mathrm{~m}$ & $1070 \mathrm{~m}$ \\
$1269 \mathrm{~m}$ & $1104 \mathrm{~m}$ \\
$1310 \mathrm{w}$ & $1240 \mathrm{vw} \mathrm{sh}$ \\
$1396 \mathrm{~s}$ & $1262 \mathrm{~m}$ \\
$1445 \mathrm{w}$ sh & $1426 \mathrm{~s}$ \\
$1609 \mathrm{~s}$ & $1626 \mathrm{~s}$ \\
$1692 \mathrm{w}$ & $1699 \mathrm{w}$ \\
$1710 \mathrm{w}$ & $1717 \mathrm{w}$ \\
& $1845 \mathrm{w} \mathrm{sh}$ \\
$2460 \mathrm{~m}$ & $2485 \mathrm{w}$ \\
& $2555 \mathrm{~m}$ \\
$3400 \mathrm{w}$ & $3400 \mathrm{vw}$ \\
$a_{\mathrm{v}}=$ very, s $=$ strong, m=medium, w=weak, sh=shoulder.
\end{tabular}

the other two bonds are longer, about 1.27 and $1.30 \AA$. The length of the last two distances indicates $\mathrm{O}(2)$ to carry the negative charge, and $\mathrm{O}(1)$ to carry the hydrogen atom, as $1.26 \AA$ is commonly observed for CO distances in oxalate ions, whereas $1.30 \AA$ has been found for corresponding distances in oxalic acid. The two $\mathrm{O}-\mathrm{C}-\mathrm{O}$ angles determined in $\mathrm{KHC}_{2} \mathrm{O}_{4}$ are both greater than $120^{\circ}$ in accordance with earlier observations. The lengthening of one bond in an $s p^{2}$ carbon-hybrid (here the $\mathrm{C}-\mathrm{C}$ bond) seems in several cases ${ }^{11,12}$ to be coupled to an opening of the angle between the other two bonds. The two $\mathrm{O}-\mathrm{C}-\mathrm{O}$ angles determined in $\mathrm{KHC}_{2} \mathrm{O}_{4}$ are, however, significantly different, the difference being $4.6^{\circ}$, and the same feature is observed in both

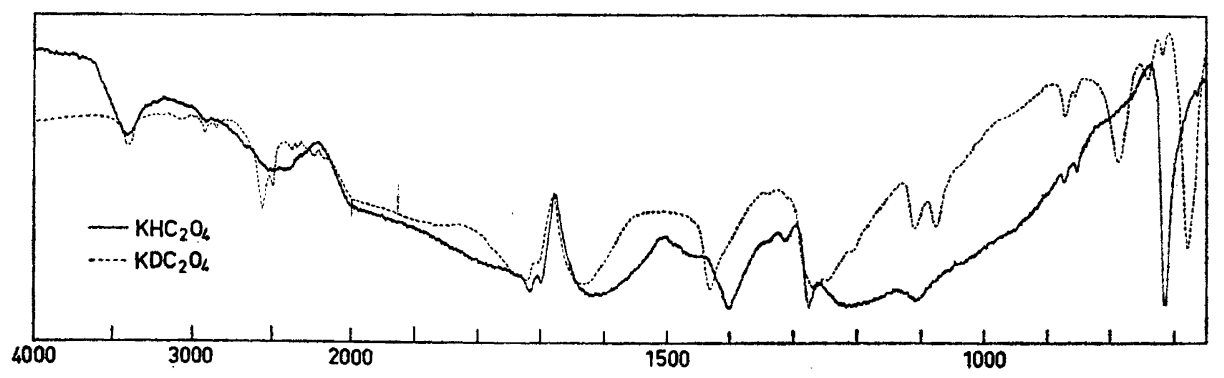

Fig. 3. Infrared spectra of $\mathrm{KHC}_{2} \mathrm{O}_{4}$ and $\mathrm{KDC}_{2} \mathrm{O}_{4}$.

Acta Chem. Scand. 22 (1968) No. 9 


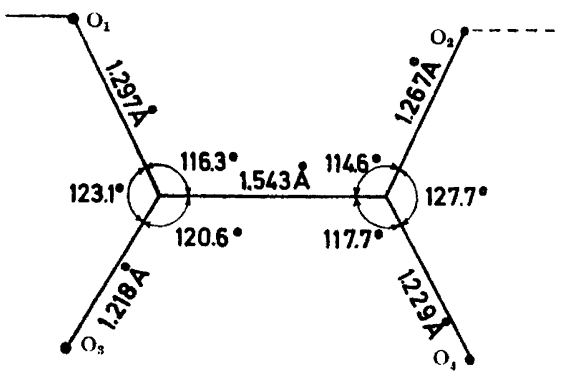

a

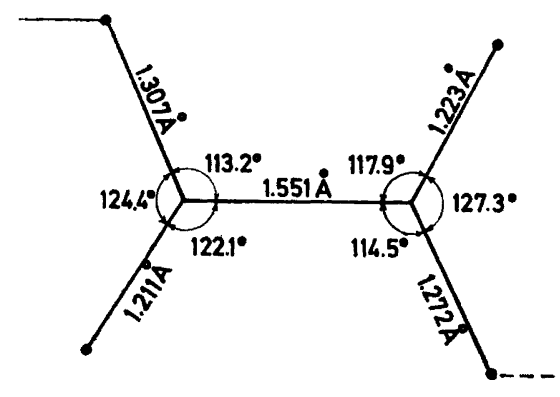

b

Fig. 4. Bond lengths and angles in the $\mathrm{HC}_{2} \mathrm{O}_{4}^{-}$ion. a: in $\mathrm{KHC}_{2} \mathrm{O}_{4}$, b: in $\mathrm{K}\left(\mathrm{HC}_{2} \mathrm{O}_{4}\right) \cdot\left(\mathrm{H}_{2} \mathrm{C}_{2} \mathrm{O}_{4}\right) \cdot 2 \mathrm{H}_{2} \mathrm{O}$ (from Ref. 2 ).

$\mathrm{K}\left(\mathrm{HC}_{2} \mathrm{O}_{4}\right) \mathrm{H}_{2} \mathrm{C}_{2} \mathrm{O}_{4} \cdot 2 \mathrm{H}_{2} \mathrm{O}$ and $\left(\mathrm{NH}_{4}\right) \mathrm{HC}_{2} \mathrm{O}_{4} \cdot \mathrm{H}_{2} \mathrm{C}_{2} \mathrm{O}_{4} \cdot 2 \mathrm{H}_{2} \mathrm{O}$ where the difference is $2.9^{\circ}$ and $2.7^{\circ}$. The $\mathrm{O}-\mathrm{C}-\mathrm{O}$ angle in different modifications of oxalic acid has earlier been determined to $126-128^{\circ}$, whereas the $\mathrm{O}-\mathrm{C}-\mathrm{O}$ angle in the oxalate ion usually has been found somewhat smaller. It is hard to find relevant chemical arguments for the difference observed. This difference approximately accounts for the difference in distance between $\mathrm{O}(1)-\mathrm{O}(3)$ and $\mathrm{O}(2)-\mathrm{O}(4)$ $\approx 0.03 \AA$, and may be related to a different bonding situation for $O(1)$ and $\mathrm{O}(2)$.

The differences observed in the two $\mathrm{C}-\mathrm{C}-\mathrm{O}$ angles near each carbon atom may be related to interactions between the oxygens and the carbon atom to which they are not directly bound as these two $\mathrm{C}-\mathrm{O}$ distances have the same length.

3. The hydrogen bond. The length of the hydrogen bond in $\mathrm{KHC}_{2} \mathrm{O}_{4}$ is found to be $2.534(8) \AA$. Unfortunately the hydrogen atom position could not unambiguously be determined from the calculated difference Fourier map. The length of the $\mathrm{C}-\mathrm{O}$ distances in the hydrogen oxalate ion, however, indicates one of the oxygen atoms to be bound to the hydrogen atom as discussed above.

Hydrogen bonds of 2.4-2.6 $\AA$ form an interesting group of study as there may be said to exist three possible potential functions for the bond. ${ }^{13}$ The first function is an asymmetric double-minimum one, with one minimum substantially lower than the other, this potential function corresponds to the bonding system $\mathrm{A}-\mathrm{H}---\mathrm{A}$, and to an asymmetric hydrogen bond. The second function is symmetric, has a single minimum, and obviously corresponds to a truly symmetric hydrogen bond. The third possible potential function is a symmetric double minimum one. If the barrier is well above the level of the ground state, then the potential corresponds to bonding in which there is an equal distribution of $\mathrm{A}-\mathrm{H}--\mathrm{A}$ and $\mathrm{A}-\mathrm{-H}-\mathrm{A}$.

Several authors 14 have correlated OH---O distances in hydrogen bonded crystals and the frequencies of infrared absorption bands attributable to the $\mathrm{OH}-$ stretching motion. This correlation, however, seems to break down for symmetrical or slightly asymmetrical bonds. The infrared spectrum of $\mathrm{KHC}_{2} \mathrm{O}_{4}$ 
is shown in Fig. 3. The absorption line at $2460 \mathrm{~cm}^{-1}$ is interpreted as the $v_{\mathrm{OH}}$ stretching vibration. Using the empirical equation of Pimentel and Cederholm ${ }^{14}$ a hydrogen bond length of $2.55 \AA$ is derived, a value which is not significantly different from the determined $H$-bond length of $2.534 \AA$. Blinc, Hadẑi and Novak, ${ }^{15}$ however, have divided compounds with short hydrogen bonds in four groups characterized by the following IR-frequencies: $1700 \mathrm{~cm}^{-1}$, $2200-2600 \mathrm{~cm}^{-1}, 3000 \mathrm{~cm}^{-1}, 3200-3300 \mathrm{~cm}^{-1}$. The hydrogen bond in $\mathrm{KHC}_{2} \mathrm{O}_{4}$ should accordingly fall in the second group which by these authors is characterized by the symmetric double minimum bond with a small barrier. This group consists of acid salts where the negative ionic charge on the proton bearing groups is characteristic. The IR-spectrum of $\mathrm{KDC}_{2} \mathrm{O}_{4}$ shows a shoulder about where the $\nu_{O D}$ stretching vibration is supposed to lie, at $1845 \mathrm{~cm}^{-1}$. There are also observable absorption lines above $2000 \mathrm{~cm}^{-1}$, but these may be due to certain combination bands (or impurities).

The bending frequencies are not easily determined as the spectra have a number of oxalate absorption bands in the region of interest, from $1700 \mathrm{~cm}^{-1}$ $1100 \mathrm{~cm}^{-1}$. Absorption lines characteristic of $\mathrm{KHC}_{2} \mathrm{O}_{4}$ are found at $1310 \mathrm{~cm}^{-1}$ and $708 \mathrm{~cm}^{-1}$, whereas in the deuterated compound characteristic lines are at $1070,785,735$, and $675 \mathrm{~cm}^{-1}$. Interpretation of these lines is not straight forward, but may possibly indicate a difference in the $\mathrm{H}$-bond in the two compounds.

Rundle ${ }^{16}$ has discussed the unusual large isotope effect observed in compounds with medium short $\mathrm{H}$-bonds having symmetric double minimum hydrogen bond potentials. The hydrogen bond in $\mathrm{HCrO}_{2}{ }^{17}$ is $0.05 \AA$ shorter than the corresponding $\mathrm{D}$-bond, and this difference has been discussed in light of different $\mathrm{H}$-bond potentials for the two cases.

$\mathrm{X}$-Ray diffractograms of $\mathrm{KHC}_{2} \mathrm{O}_{4}$ and $\mathrm{KDC}_{2} \mathrm{O}_{4}$ show the two compounds to be structurally very similar. Slow scans were recorded for the compounds to determine the difference in unit cell dimensions when hydrogen is exchanged with deuterium. A difference is detectable, the dimensions of $\mathrm{KDC}_{2} \mathrm{O}_{4}$ being somewhat greater than for $\mathrm{KHC}_{2} \mathrm{O}_{4}$, about $0.015 \AA$ in the $a$ and $c$ axes, whereas the $b$-axis seems to be unchanged. These small differences are reasonable, but show that the isotope effect is small. A simple estimate shows that the $\mathrm{O}-\mathrm{D}-\mathrm{O}$ distance is $2.54 \AA, 0.005 \AA$ larger than the $\mathrm{O}-\mathrm{H}--\mathrm{O}$ distance. However, some care must be exercised in using unit cell changes as the basis for isotope effects. ${ }^{18}$ In this simple system, however, with only one independent $H$-bond in the crystallographic unit, one should be conceivably justified in deriving bond length changes from lattice constant changes.

From the different indications described above we are tempted to conclude that the hydrogen bond potential in $\mathrm{KHC}_{2} \mathrm{O}_{4}$ is asymmetric. This conclusion is based partly on the difference in $\mathrm{C}-\mathrm{O}$ bond lengths indicating the $\mathrm{C}-\mathrm{O}(1)$ bond to carry the hydrogen atom, and partly on the infrared spectrum which shows the $\nu_{\mathrm{OH}}$ stretching vibration at $2460 \mathrm{~cm}^{-1}$ inferring an $\mathrm{H}$-bond length of $2.55 \AA$ in agreement with the observed value, and also supported by the absence of a strong isotope effect upon deuterium substitution. 
Acknowledgement. This work has been supported by The Royal Norwegian Council for Scientific and Industrial Research. I also want to thank Mrs. T. L. Rolfsen for extensive technical assistance, and other members of the staff for stimulating discussions. Finally I will express my thanks to the crystallographic group, Chem. Dept. C, University of Oslo, for use of their computer programs.

\section{REFERENCES}

1. Hendricks, S. B. Z. Krist. 91 (1935) 48.

2. Haas, D. J. Acta Cryst. 17 (1964) 1511.

3. Currie, M., Speakman, J. C. and Curry, N. A. J. Ohem. Soc. A 19671862.

4. International Tables for X-ray Crystallography, Kynoch Press, Birmingham 1952, Vol. I.

5. International Tables for X-ray Crystallography, Kynoch Press, Birmingham 1962, Vol. III, p. 258.

6. Pedersen, B. F. Acta Chem. Scand. 21 (1967) 801.

7. Program No. 384 (modified for use on Univac 1107): IUCr World List of Crystallographic Computer Programs, (1962).

8. Robertson, J. H. Acta Cryst. 18 (1965) 410.

9. Murata, H. and Kawaii, K. J. Chem. Phys. 25 (1956) 796.

10. Murata, H. and Kawaii, K. J. Chem. Phys. 25 (1956) 589.

11. Pedersen, B. Acta Cryst. B24 (1968) 478.

12. Sass, R. L. and Scheuerman, R. F. Acta Cryst. 15 (1962) 77.

13. Ibers, J. A. Ann. Rev. Phys. Chem. 16 (1965) 384.

14. Rundle, R. E. and Parasol, M. J. J. Chem. Phys. 20 (1952) 1487; Lord, R. C. and Merrifield, R. E. J. Chem. Phys. 21 (1953) 166; Lippincott, E. R. and Scroeder, R. J. Chem. Phys. 23 (1955) 1131; Nakamoto, K., Margoshes, M. and Rundle, R. E. J. Am. Chem. Soc. 77 (1955) 6480; Pimentel, G. C. and Sederholm, C. H. J. Chem. Phys. 24 (1956) 639.

15. Blinc, R., Hadżi, D. and Novak, A. Z. Electrochem. 64 (1960) 567.

16. Rundle, R. E. Journ. Phys. 25 (1964) 487.

17. Snyder, R. G. and Ibers, J. A. J. Chem. Phys. 36 (1962) 1356.

18. Delaplane, R. G. and Ibers, J. A. J. Chem. Phys. 45 (1966) 3451.

Received March 29, 1968. 